\title{
Assessment of the W7-X High Heat Flux Divertor with Thermo- mechanical Analysis
}

\author{
Xinyuan Qian ${ }^{\mathrm{a}, \mathrm{b}}$, Xuebing Peng ${ }^{\mathrm{b} *}$, Joris Fellinger ${ }^{\mathrm{c}}$, Jean Boscary ${ }^{\mathrm{d}}$, Victor Bykov ${ }^{\mathrm{c}}$, Zhongwei Wang ${ }^{\mathrm{b}}$, \\ Minyou Ye ${ }^{\mathrm{a}, \mathrm{b}}$, Yuntao Song ${ }^{\mathrm{b}, \mathrm{a}}$ \\ ${ }^{a}$ School of Nuclear Science and Technology, University of Science and Technology of China, Jinzhai Road 96, 230026 \\ Hefei Anhui, PR China \\ ${ }^{b}$ Institute of Plasma Physics, Chinese Academy of Sciences, Shushanhu Road 350, 230031 Hefei Anhui, PR China \\ ${ }^{c}$ Max Planck Institute for Plasma Physics, Wendelsteinstr. 1, 17491 Greifswald, Germany \\ ${ }^{d}$ Max Planck Institute for Plasma Physics, Boltzmannstr. 2, 85748 Garching, Germany
}

\begin{abstract}
The Wendelstein 7-X is an experimental device designed with a stellarator magnetic confinement for stationary plasma operation (up to 30 minutes). At the first stage, it is scheduled to start with an inertially cooled test divertor unit and a shorter plasma pulse operation up to $10 \mathrm{sec}$. After the completion of this stage, a water-cooled high heat flux (HHF) divertor will be installed for the steady-state operation phase. The divertor consists of individual target modules, which are sets of target elements armored with CFC tiles supported by a stainless steel structure and fed in parallel with manifolds. Detailed thermo-mechanical analysis of the target modules using the finite element method has been performed to validate and/or improve the elected design of the HHF divertor under operation. Different operating conditions have been studied and the effect of the variation of the convective heat flux pattern with localized heating loads as high as $10 \mathrm{MW} / \mathrm{m}^{2}$ onto the target elements has been computed. The analysis of the thermal response, stress distribution and deformation allowed a better understanding of the behavior of the divertor modules under operation and confirmed the suitability of the design.
\end{abstract}

Keywords: Wendelstein 7-X; plasma facing component; divertor; thermo-mechanical

\section{Introduction}

The Wendelstein 7-X (W7-X), constructed at Greifswald (Germany), is an experimental device with a stellarator magnetic confinement for stationary plasma operation. The goal of the device is to demonstrate the feasibility of the advanced stellarator concept as a candidate for a future fusion reactor [1].

For its long pulse operation phase, a water-cooled high heat flux (HHF) divertor, consisting of 120 individual target modules (TMs), will be installed. It is designed to withstand convective thermal loads up to 10 $\mathrm{MW} / \mathrm{m}^{2}$ [2] and additional electron cyclotron resonance heating (ECRH) stray radiation developed by reflection and scattering of the ECRH beam [3]. Since the modules have a low absorption coefficient for microwaves, the whole parts of the attachment system of the divertor absorb about $300 \mathrm{~W} / \mathrm{m}^{2}$ of ECRH stray radiation.

A schematic view of the TM and element arrangement in one divertor unit is shown in figure 1 in [4]. There are 12 different types of TMs. Each module is a set of target elements (TEs) armored with CFC tiles mounted onto a stainless steel (SS) structure and fed in parallel with manifolds. A series of work including both HHF tests [5-7] and finite element simulations [8-10] has been performed to check the thermo-mechanical behavior of different parts of the divertor modules.

Previous detailed thermo-mechanical analysis has been performed on the TM9H module to support and complement the testing of the full-scale prototype of the same type [7, 9]. This work identified critical areas such as the weld of water manifold holders and the transition between the water connectors of the TEs and the cooling pipes [10]. Based on the results of this analysis, the design of the TMs has been improved on well identified points and implemented in the production drawings. This analysis also confirmed the suitability of the basic design.

This paper presents the analysis of one additional type, namely $\mathrm{TM} 2 \mathrm{H}$, of divertor modules. The main difference with TM9H is the size and the quantity of TEs. TM2H has 7 TEs, each TE is $578 \mathrm{~mm}$ long; TM9H has 12 TEs, and each TE is $361 \mathrm{~mm}$ long [7-9].

\section{Design of the target modules TM2H}

A TE is made of CFC bi-layer tiles as plasma facing material which are electron beam welded onto a $\mathrm{CuCrZr}$ heat sink, seen in figure 1 . The thickness of $\mathrm{CFC}, \mathrm{Cu}-$ interlayer and CuCrZr is about $7 \mathrm{~mm}, 3 \mathrm{~mm}$ and $19 \mathrm{~mm}$, respectively. A TE is about $57 \mathrm{~mm}$ wide and $593 \mathrm{~mm}$ long. There are 23 tiles on each target. The gap between two adjacent tiles is about $\pm 0.2 \mathrm{~mm}$.

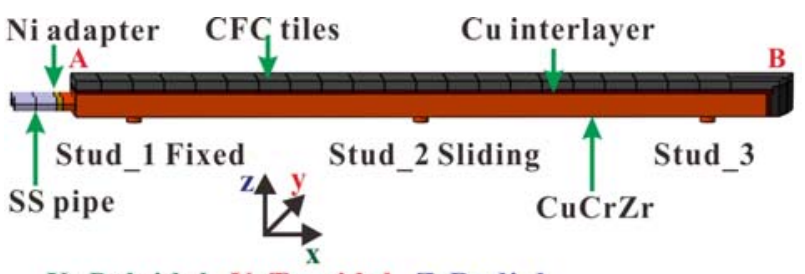

X: Poloidal Y: Toroidal Z:Radial

Fig. 1 Model of target element

Each TE is mounted on the plate by 3 studs as shown in figure 1 . The stud near the water connectors fully fixes the TEs on the plate. The middle stud provides $2 \mathrm{~mm}$ translational motion both positive and 
negative along the poloidal direction to allow thermal expansion. Both of these two studs prevent movements along radial direction. The function of the last stud is only to keep all TEs together. An independent rail from the support structure connects all the TEs of one TM together to avoid leading edge effects.

The different parts of TM2H are shown in figure 2. The function of the limiter rod placed between rail-1 and rail-2 with an initial gap of $0.2 \mathrm{~mm}$ to TEs is to restrict the downward motion amplitude. Four connectors at bottom of the plate provide an attachment to the plasma vessel side. Each connector has different translation degrees of freedom as shown in figure 3 , to avoid overconstrained assembly and provide enough stiffness at the same time.

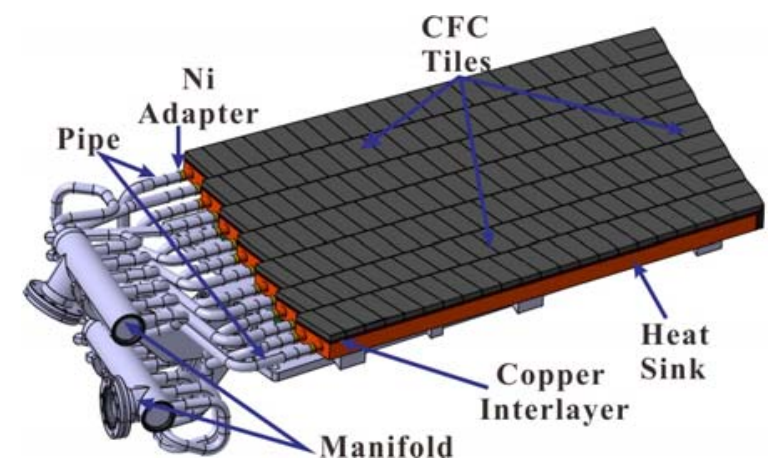

Fig. 2 Plasma side view of TM2H module

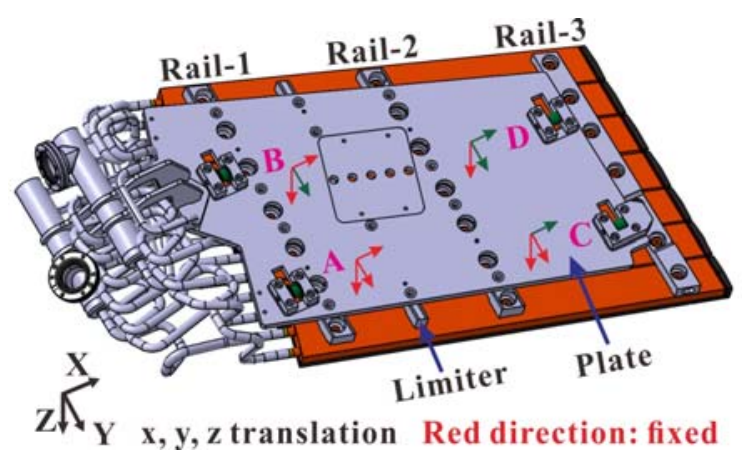

Fig. 3 Plasma vessel side view of TM2H module

\section{Thermo-mechanical calculations of TM2H}

The scope of the analyses is to estimate the temperature levels, stresses and displacement for the module. Material properties are shown in table 1.

The load pattern deposition onto the divertor surface is based on physics modeling [11]. The local peak heat load on target element is $10 \mathrm{MW} / \mathrm{m}^{2}$ and its spatial scope is $80-150 \mathrm{~mm}$ poloidally. Two possible thermal load cases without consideration of radiation have been performed: (a) case 1 with $10 \mathrm{MW} / \mathrm{m}^{2}$ over 10-13 tiles from pipe side for all TEs and $300 \mathrm{~W} / \mathrm{m}^{2}$ ECRH heat load on all surface; (b) case 2 with 10 $\mathrm{MW} / \mathrm{m}^{2}$ over 15-18 tiles from pipe side for all TEs and $300 \mathrm{~W} / \mathrm{m}^{2} \mathrm{ECRH}$ heat load on all surface. The heat transfer coefficient is about $90 \mathrm{~kW} /\left(\mathrm{m}^{2} . \mathrm{K}\right)$ and the temperature of inlet water is set at $60{ }^{\circ} \mathrm{C}$. In both cases, the maximum temperature on the CFC surface doesn't exceed $1050{ }^{\circ} \mathrm{C}$, as shown in figure 4 . It is a little bit higher than the results from prior calculations [7-9] mainly because the radiation from the CFC tiles to the ambient was not considered. The maximum temperature of interlayer and heat sink are $543{ }^{\circ} \mathrm{C}$ and $375{ }^{\circ} \mathrm{C}$, respectively, which are acceptable. The maximum temperature of the plate is about $200{ }^{\circ} \mathrm{C}$ with $300 \mathrm{~W} / \mathrm{m}^{2}$ ECRH heat load.

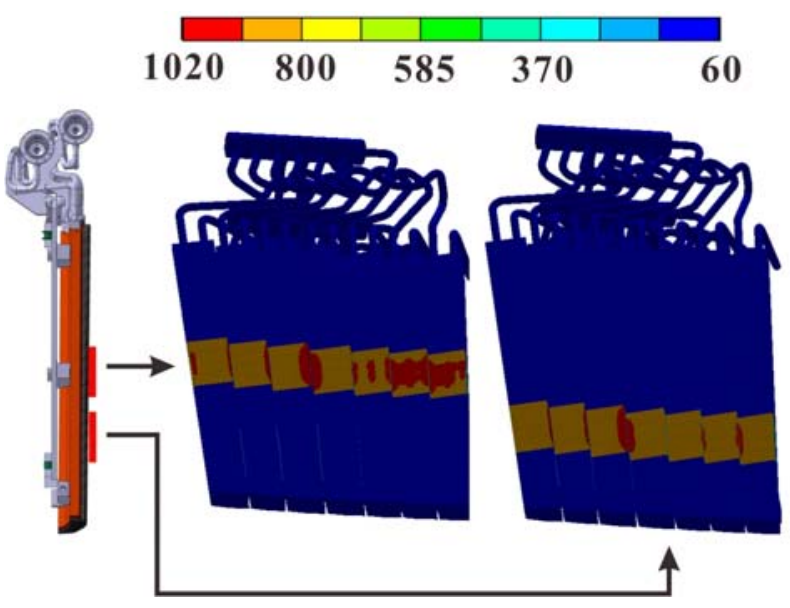

Fig. 4 Results of the thermal calculation for two load cases

Table 1. Temperature dependent properties of the materials

\begin{tabular}{|c|c|c|c|c|c|}
\hline Materials & & $\begin{array}{c}\text { Thermal conductivity } \\
{[\mathrm{W} /(\mathrm{m} \bullet \mathrm{K})]}\end{array}$ & $\begin{array}{c}\text { Thermal expansion } \\
{\left[10^{-6} 1 / \mathrm{K}\right]}\end{array}$ & $\begin{array}{c}\text { Young's modulus } \\
\text { [GPa] }\end{array}$ & $\begin{array}{c}\text { Allowable Stress } \\
\text { [MPa] }\end{array}$ \\
\hline \multirow[t]{3}{*}{ CFC } & Poloidal & 85 at $20^{\circ} \mathrm{C}, 40$ at $1000^{\circ} \mathrm{C}$ & 1.5 & 13.5 & \\
\hline & Toroidal & 120 at $20^{\circ} \mathrm{C}, 55$ at $1000^{\circ} \mathrm{C}$ & 1.5 & 13.5 & \\
\hline & Radial & 325 at $20^{\circ} \mathrm{C}, 145$ at $1000^{\circ} \mathrm{C}$ & 0.4 & 107 & \\
\hline \multirow[t]{2}{*}{ AMC_Cu } & & 125 at $20^{\circ} \mathrm{C}$ & 15 at $20^{\circ} \mathrm{C}$ & 127.5 at $20^{\circ} \mathrm{C}$ & 135 (yield limit) \\
\hline & & 190 at $600{ }^{\circ} \mathrm{C}$ & 23 at $600{ }^{\circ} \mathrm{C}$ & 86 at $700{ }^{\circ} \mathrm{C}$ & \\
\hline \multirow[t]{2}{*}{ CuCrZr } & & 320 at $20^{\circ} \mathrm{C}$ & 16.8 at $20^{\circ} \mathrm{C}$ & 127.5 at $20^{\circ} \mathrm{C}$ & 396 (3*Sm) \\
\hline & & 170 at $600{ }^{\circ} \mathrm{C}$ & 19 at $700{ }^{\circ} \mathrm{C}$ & 86 at $700{ }^{\circ} \mathrm{C}$ & \\
\hline SS & & 15 & 14 & 200 & $525(3 * S m)$ \\
\hline Nickel & & 90 & 13 & 207 & 120 \\
\hline
\end{tabular}


Table 2. Maximum equivalent (von-Mises) stress of each component (MPa)

\begin{tabular}{lllllll}
\hline Load cases & Manifold & Pipe & Ni adaptor & Heat sink & Rail & Plate \\
\hline 1 & 178 & 41 & 17 & 39 & 3 & 1.2 \\
2 & 178 & 51 & 26 & 59 & 436 & 232 \\
3 & 180 & 42 & 24 & 276 & 277 & 327 \\
4 & 184 & 49 & 26 & 305 & 256 \\
\hline
\end{tabular}

The thermo-mechanical loads were the temperature field distribution from thermal calculation and 2.8 $\mathrm{MPa}$ water pressure. Mechanical boundary conditions were applied to the four connectors, marked as A, B, C, and D as shown in figure 3 . The translation degrees of freedom of each connector were defined in the local coordinate, seen in figure 3 . Besides, the rotation degrees for all connectors were free around local $\mathrm{X}$ direction and fixed around other two directions.

Four mechanical load cases were investigated: (1) case 1 with $2.8 \mathrm{MPa}$ water pressure only; (2) case 2 with $2.8 \mathrm{MPa}$ water pressure and temperature distribution calculated with $300 \mathrm{~W} / \mathrm{m}^{2}$ ECRH heat load on all surface; (3) case 3 with $2.8 \mathrm{MPa}$ water pressure and temperature distribution calculated from thermal load case 1; (4) case 4 with $2.8 \mathrm{MPa}$ water pressure and temperature distribution calculated from thermal load case 2 .

The results listed in table 2 of all load cases indicate that, (i) stresses in manifold, pipe and $\mathrm{Ni}$ adaptor are mainly caused by the water pressure; (ii) ECRH thermal load has a significant influence on the rail and plate; (iii) stress of heat sink mostly caused by the temperature gradient when HHF load applied.

In case 3, the HHF load is over the rail-2 while it is between rail-2 and rail-3 in case 4 . So, the thermal expansion of heat sink has more influence on the contact between heat sink and rail in case 3. Unsurprisingly, the maximum stress appears in a very small region of stud in case 3 . It is larger than that in case 4 as listed in table 2 because of stress concentration. In reality, it will decrease as soon as some local plastic deformation occurs in this region. While in case 4, it appears in the top surface of heat sink and the stress distribution under the HHF load tiles in the top surface of heat sink basically the same for both case 3 and case 4 . All the stresses calculated are within the thermal stress limits for the corresponding materials.

The middle stud can slide along the poloidal direction as shown in figure 1 . The simulation results reveal that the maximum relative displacement between middle stud and rail along the direction are about $0.29 \mathrm{~mm}$ and $0.14 \mathrm{~mm}$, respectively, which is within the design limit.

The calculated results of radial displacement for case 3 and case 4 are shown in figure 5 and figure 6 . The positive and negative values signify the movements upwards and downwards, respectively.
Directional Deformation (Z Axis)

Unit: mm

Coordinate System

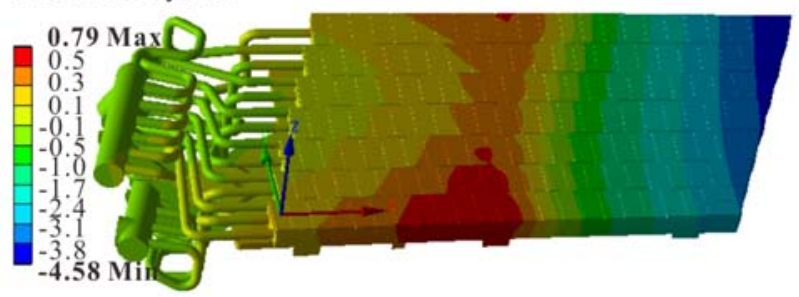

Fig. 5 Displacement in radial direction of case 3

Directional Deformation (Z Axis)

Unit: $\mathbf{m m}$

Coordinate System

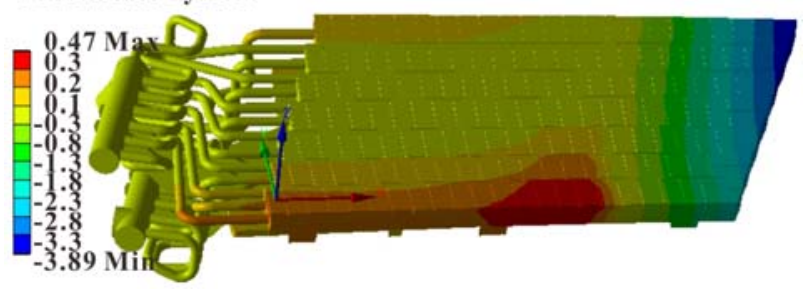

Fig. 6 Displacement in radial direction of case 4

One of the TEs was taken out to investigate the mechanical behavior of the radial displacement. The profiles of the radial deflection along the path from A to $B$ (see figure 1) for both case 3 and case 4 are presented in figure 7.

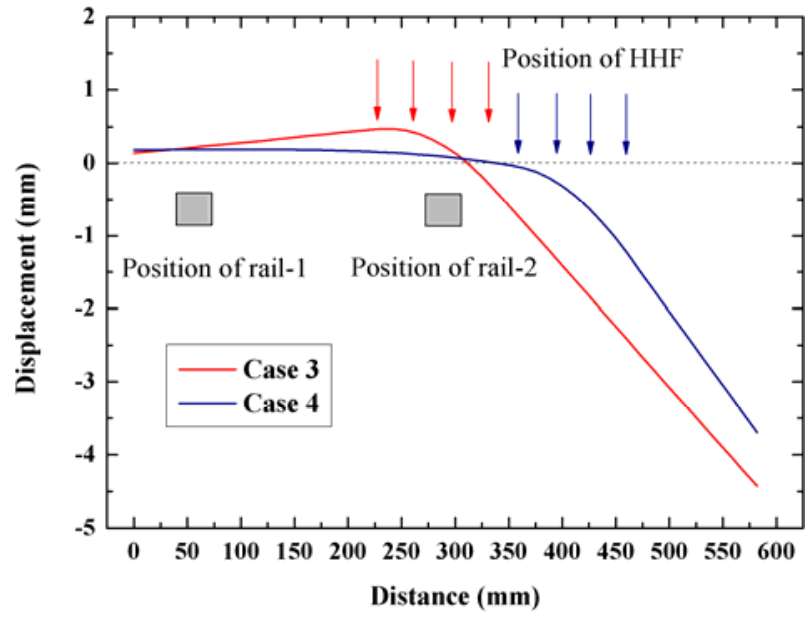

Fig. 7 Profiles of the radial deflection along the path from A to B for both case 3 and case 4

Figure 7 indicates the location of the rails and of the convective loads. First of all, the stud_1 and stud_2 are connected to rail-1 and rail-2 respectively which prevent movements perpendicularly to the rails. Between those 
two rails, it has high upwards displacement in case 3 due to the fact that the thermal expansion of HHF load area in the top surface of TE is higher than that of bottom surface. In the right side of rail-2, the TE has gradual increase downwards displacement along poloidal direction since it is like a cantilever in this side. The deflection is amplified with the distance from rail-2 increasing.

\section{Conclusions}

The thermo-mechanical analysis of TM2H indicates that the temperature of all parts is acceptable for long pulse operation.

With a detailed study of the stress calculated in all situations, the results show that the stress of different parts in the module is mainly caused by water pressure, ECRH load and HHF load respectively.

Based on current results of radial displacement, the design still needs to be verified in order to keep the deflection in an appropriate range to avoid generating leading edge effects (limitation of steps up to $0.2 \mathrm{~mm}$ between neighboring target elements during operation), These data will be used to refine the required space with neighboring components of the divertor systems to avoid possible collision during operation. The design of the TMs has been confirmed and the manufacturing process of the TMs can be pursued without expectation of major changes.

\section{References}

[1] H. Renner et al., The capabilities of steady state operation at the stellarator W7-X with emphasis on divertor design, Nucl. Fusion 40 (6) (2000) 1083-1093.
[2] J. Boscary et al., Pre-series and testing route for the serial fabrication of W7-X target elements, Fusion Eng. Des. 84 (2) (2009) 497-500.

[3] H.J. Hartfuss, R. König and A. Werner, Diagnostics for steady state plasmas, Plasma Phys. Control. Fusion 48 (10) (2006) R83-R150

[4] J. Boscary et al., Development activities for the target elements of the Wendelstein 7-X divertor, Fusion Eng. (2013), IEEE 25th Symposium on Fusion Engineering (SOFE) 1-6

[5] H. Greuner et al., High heat flux tests of the WENDELSTEIN 7-X pre-series target elements: Experimental evaluation of the thermo-mechanical behavior, Fusion Eng. Des. 82 (15) (2007) 1713-1719

[6] H. Greuner et al., Performance and statistical quality assessment of CFC tile bonding on the pre-series elements of the Wendelstein 7-X divertor, Fusion Eng. Des. 86 (9) (2011) 1685-1688

[7] A. Peacock et al., Status of high heat flux components at W7-X, IEEE Trans. Plasma Sci. 42 (3) (2014) 524 - 532.

[8] M. Y. Ye et al., Thermo-mechanical analysis of the Wendelstein 7-X divertor, Fusion Eng. Des. 86 (9) (2011) 1630-1633

[9] X. B. Peng et al., Thermo-mechanical analysis of Wendelstein 7-X plasma facing components, Fusion Eng. Des. 88 (9) (2013) 1727-1730

[10] M. Smirnow et al., Mechanical examination and analysis of W7-X divertor module sub-structures, Fusion Eng. Des. 98-99 (2015) 1399-1402

[11] P. Grigull et al., Divertor operation in stellarators: results from W7-AS and implications for future devices, Fusion Eng. Des. 66-68 (2003) 49-58. 